\title{
Methods and Mechanism of Powder Mixing for Selective Laser Melting
}

Guang Yang* (0000-0003-3406-964X), Yilian Xie (0000-0002-5059-0366), Shuo Zhao (0000-0003-1869-3012), Yuhang Ren (0000-0002-1394-6773), Chao Wang (0000-0003-0055-9894)

School of Mechanical Engineering, Shenyang Aerospace University, Shenyang 110136, China

*Corresponding author: Yang Guang, Ph.D., Professor, School of Mechanical Engineering, Shenyang Aerospace University, Shenyang 110136, P. R. China, Tel: 0086-24-89723852, E-mail: yangguang@sau.edu.cn

Selective laser melting (SLM) technology has strict demand to its powder materials which is needed to be spread evenly and conducted laser sintering layer by layer. Therefore, the uniformity and flatness of powder bed are the basic conditions for processing. Ball milling is an important composite powder preparation process of SLM. Three kinds of ball milling processes, dry ball milling, wet ball milling and hollow milling with various parameters are adopted to prepare TC4 / $\mathrm{TiB}_{2}$ composite powder. It is concluded that a milling time $8 \mathrm{~h}$ at a speed of $230 \mathrm{rpm}$ without milling ball is proved the optimal working condition to make the composite powder maintain good spherical shape and ensure the mixing uniformity. The mechanism of three kinds of powder mixing effects is revealed by analyzing the dynamic relationship and hardness of the milling ball, TC4 and $\mathrm{TiB}_{2}$ particle. This work provides an important reference for the preparation of high quality $\mathbf{T C 4} / \mathbf{T i B}_{2}$ composite powder for SLM.

Keywords: Ball Milling, Powder Mixing, TC4 / TiB 2 composite powder, Selective Laser Melting

\section{Introduction}

Selective laser melting (SLM) is a high-precision rapid prototyping technology based on the powder laying and laser melting layer by layer. During SLM process, the metal powder is laid on the special substrate of the machine in advance, and then the selective scanning is carried out on the powder bed with a laser beam. After each powder layer is sintered and formed, the height of the substrate decreases by one layer, and the powder scraping tool could lay another powder layer. The laser continues to scan the powder bed, and this process is repeated until the part is processed. SLM technology can make the formed parts obtain higher density and have better mechanical properties due to the higher laser power density, thus having broad application prospects [1 - 5].

Titanium and titanium matrix composites have become research highlights in recent years, and the titanium matrix powder being processed by using SLM has also been emerging topics in high-end manufacturing industry [6 - 9]. The porosity, cracks and deforming defects usually occur on the formed parts due to quickly melting, cooling and solidifying of the metal powder material in a short time. In addition, if the powder layer is not melted enough, some problems such as balling effect may occur easily to produce powder sticking and slag hanging in suspended parts manufacturing. Therefore, it is very important to prepare the raw materials (powder) of titanium and titanium matrix composites for SLM processing, and the quality of the powder is closely related to that of the
SLM parts.

The development of mixed powders can greatly enrich the diversity of titanium matrix composites. Therefore, a lot of researchers began to carry out relevant studies in order to promote the SLM manufacturing. The influence of vacuum inert gas atomization (VIGA) and electrode induction melting gas atomization (EIGA) process on the performance of NiTi alloy powder which is prepared for SLM was compared by Zheng et al [10], and found that the NiTi powder was prepared using EIGA could satisfy the requirements of SLM. Attar et al [11] prepared a Ti-TiB composite powder by ball milling and processed a fully dense SLM forming part. The carbon nanotubes reinforced aluminum matrix powders were prepared using ball milling process by Yang [12]. Attar et al. [13] studied the particle shape induced by milling time of Ti-TiB composite powder. It was found that powder made by lower milling time has better spherical shape which facilitates the density and compression performance of SLM forming parts. Shen et al [14] investigated the effect of ball milling process on $\mathrm{B}_{4} \mathrm{C}-\mathrm{Al}$ composite performance, and indicated that the milling velocity and time are important factors to the particle distribution and interfacial bonding. Jung et al [15] observed that dry milled boron particles showed rougher surface morphology than wet one.

The above investigations pointed out the requirements of SLM on powder shape and uniformity as well as the selection principle of ball milling process parameters, which provides a good reference for powder mixing of titanium matrix composites. Three TC4 
/ $\mathrm{TiB}_{2}$ ball milling powder mixing methods for SLM are proposed with the mechanism revealing in this paper.

\section{Materials and method}

\subsection{Powder materials and method}
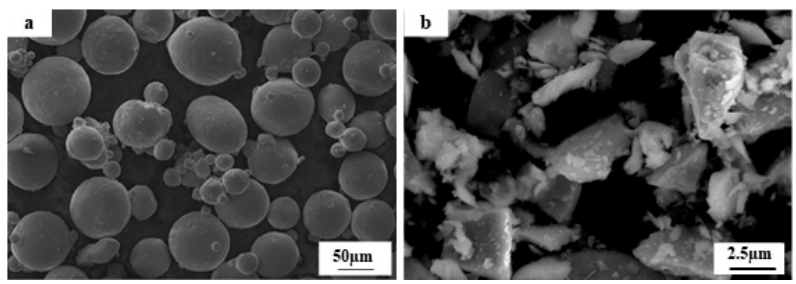

Fig. 120 - $53 \mu \mathrm{m}$ TC4 powder (a) and 0.5 - 3 um TiB2 powder

The thickness of the fusible powder layer of SLM technology is $15-100 \mu \mathrm{m}$. In order to fully mix the reinforced $\mathrm{TiB}_{2}$ particles with TC4 powder, the diameter of $20-53 \mu \mathrm{m}$ TC4 and $0.5-3 \mu \mathrm{m} \mathrm{TiB}_{2}$ are taken as the materials in the experiment, and the powder morphology is shown in Fig. 1.

Besides the mixed powder, the diameter and material of the milling ball is $3 \mathrm{~mm} \mathrm{ZrO}_{2}$; the anhydrous ethanol is used as the milling media in the experiment.

\subsection{Ball milling methods}

\section{(1) Dry ball milling powder mixing}

Two metal powders and a certain proportion of ball material without any medium are adopted for dry ball milling powder mixing. The $\mathrm{ZrO}_{2}$ particle with high hardness and diameter of $3 \mathrm{~mm}$ is used as the milling ball in the experiment; The rotating speed of the ball mill is $230 \mathrm{rpm}$. The mixed powder ratio is wt $\% 95 \mathrm{TC} 4$ with $\mathrm{wt}^{\circ} \% 5 \mathrm{TiB}_{2}$, the process parameters of dry ball milling powder mixing are shown in Table 1.

Tab. 1 Process parameters of $d r y$ ball milling powder mixing

\begin{tabular}{ccc}
\hline No. & Milling time $(\mathrm{h})$ & Ratio of ball to powder $(\mathrm{wt} \%)$ \\
\hline I & 4 & $5: 1$ \\
\hline II & 6 & $5: 1$ \\
\hline III & 8 & $5: 1$ \\
\hline IV & 10 & $5: 1$ \\
\hline V & 12 & $5: 1$ \\
\hline
\end{tabular}

\section{(2) Wet ball milling powder mixing}

The anhydrous ethanol as the ball milling medium is added into the dry ball milling powder mixing process. The function of the medium is to reduce the high heat generated in the ball milling and slow down the impact force. This batch of wet milling powder mixing experiments are based on the dry one. The ball milling time is changed to 4, 6 and 8 hours, the ball milling speed; other working conditions such as the ratio of milling ball and titanium alloy material are consistent with the dry milling powder mixing. The process parameters of wet ball milling powder mixing are shown in Table 2.

Tab. 2 Process parameters of wet ball milling powder mixing

\begin{tabular}{ccc}
\hline No. & Milling time $(\mathrm{h})$ & Ratio of ball to powder $\left(\mathrm{wt}^{\mathrm{0}} \%\right)$ \\
\hline VI & 4 & $5: 1$ \\
\hline VII & 6 & $5: 1$ \\
\hline VIII & 8 & $5: 1$ \\
\hline
\end{tabular}

\section{(3) Hollow milling powder mixing}

Based on the previous two powder mixing methods, the concept of hollow milling powder mixing is conducted, and the powders are tried to be mixed by using the planetary ball mill at high rotation speed and vacuum environment without milling ball. The ball milling parameters and the ratio of mixed powder are consistent with the previous two groups of mixing experiments. The ball mill speed is $230 \mathrm{rpm}$ and the mixing ratio was $\mathrm{wt}^{\circ} \% 95 \mathrm{TC} 4$ with $\mathrm{wt}^{\mathrm{O}} \% 5 \mathrm{TiB}_{2}$. The parameters are shown in Table 3 .

Tab. 3 Process parameters of hollow milling powder mixing

\begin{tabular}{cc}
\hline No. & Milling time $(\mathrm{h})$ \\
\hline IX & 4 \\
\hline X & 6 \\
\hline XI & 8 \\
\hline
\end{tabular}




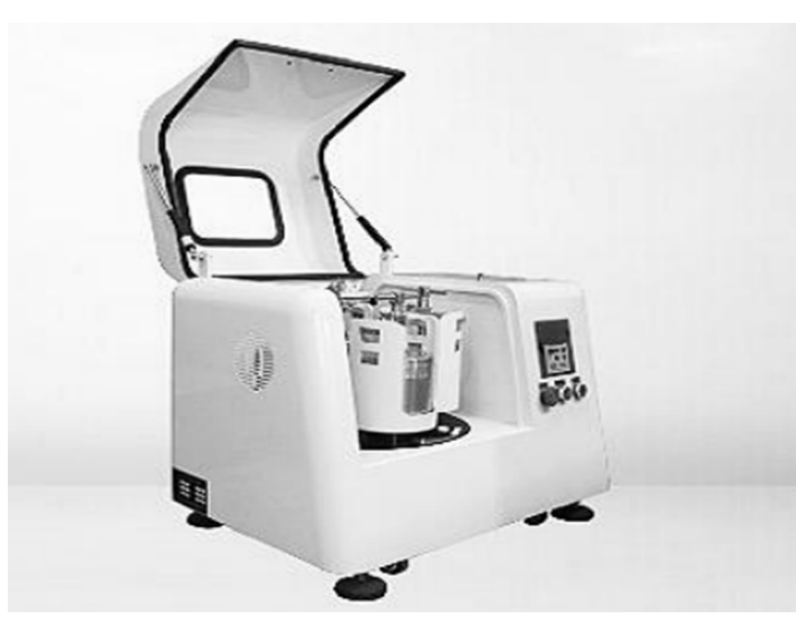

Fig. 2 YXQM planetary ball mill

A planetary ball mill can mill and mix various materials and particle sizes by dry and wet methods is adopted in the experiment as shown in Fig. 2. The minimum particle size of milling products can reach 100 $\mathrm{nm}$. In the ball milling process, the vacuum ball milling tank can be used to mix the powder in the oxygen isolating state.

\section{Results and discussion}

\subsection{Morphological evolution of milled TC4/ $\mathrm{TiB}_{2}$ powder}

(1) Dry ball milling powder mixing

The five samples obtained from the experiment I$\mathrm{V}$ are scanned by electron microscope. Fig. 3 shows the morphological images of dry ball milling mixed powder for $4 \mathrm{~h}, 6 \mathrm{~h}, 8 \mathrm{~h}, 10 \mathrm{~h}$ and $12 \mathrm{~h}$ respectively. After dry ball milling, the TC4 particle surface becomes rough as shown in Fig. 3. The results showed that with the increase of the ball milling length, the powder particles deteriorated, and the number and maximum size of flat particles increased as the ball milling length increased, at $12 \mathrm{~h}$, the maximum irregular flat particles exceeded $150 \mu \mathrm{m}$.

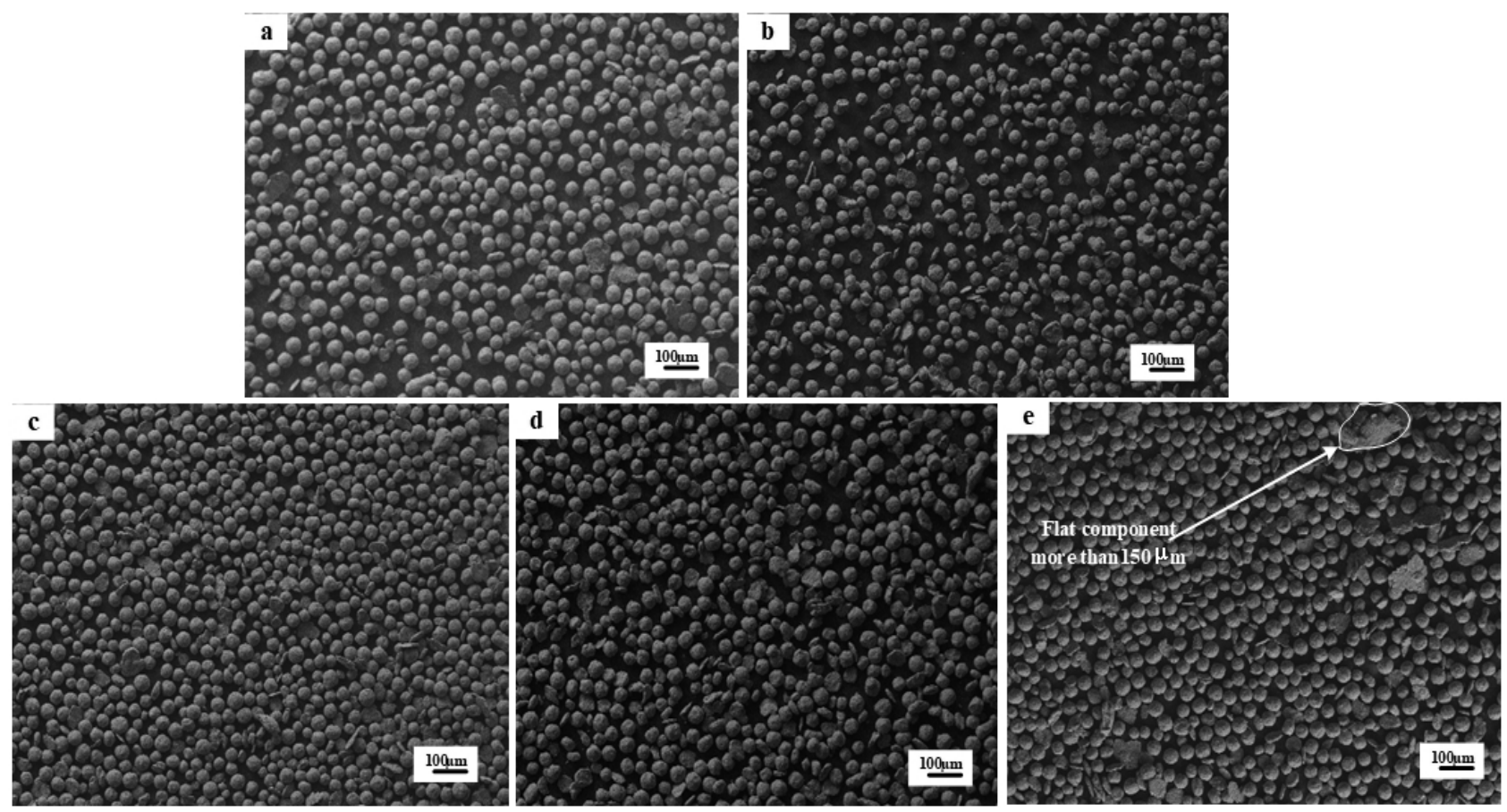

Fig. 3 Morphological images of dry ball milling mixed powder for $4 \mathrm{~h}(\mathrm{a}), 6 \mathrm{~h}(\mathrm{~b}), 8 \mathrm{~b}(\mathrm{c}), 10 \mathrm{~b}$ (d) and $12 \mathrm{~h}(\mathrm{e})$

The powder scanning diagram is partially enlarged as shown in Fig. 4 (a). It can be seen that the large particles are TC4, these particles have extrusion deformation and welding during dry ball milling. The size of $\mathrm{TiB}_{2}$ particles is nearly 100 times smaller than that of TC4 particles. In order to confirm that most small $\mathrm{TiB}_{2}$ particles are pinned to large TC4 particles, higher magnification and energy spectrum analysis were performed on the milled $\mathrm{TC} 4 / \mathrm{TiB}_{2}$ powder as shown in Fig. 4 (b), 4 (c), 4 (d). It can be found that from the energy spectrum analysis the spectrum 1 mainly contains $\mathrm{B}$ and $\mathrm{Ti}$, indicating that the small fragments in this area are $\mathrm{TiB}_{2}$ particles, which proves that the small particle size $\mathrm{TiB}_{2}$ is indeed pinned (or welded) to the large particle TC4 during dry ball milling. Similar spectrum 2 contains $\mathrm{B}, \mathrm{Ti}, \mathrm{Al}$ and $\mathrm{V}$. That is, the regions of spectrum 2 contain not only $\mathrm{TiB}_{2}$ fragments but also TC4 fragments, indicating that TC4 particles are broken during dry ball milling. 

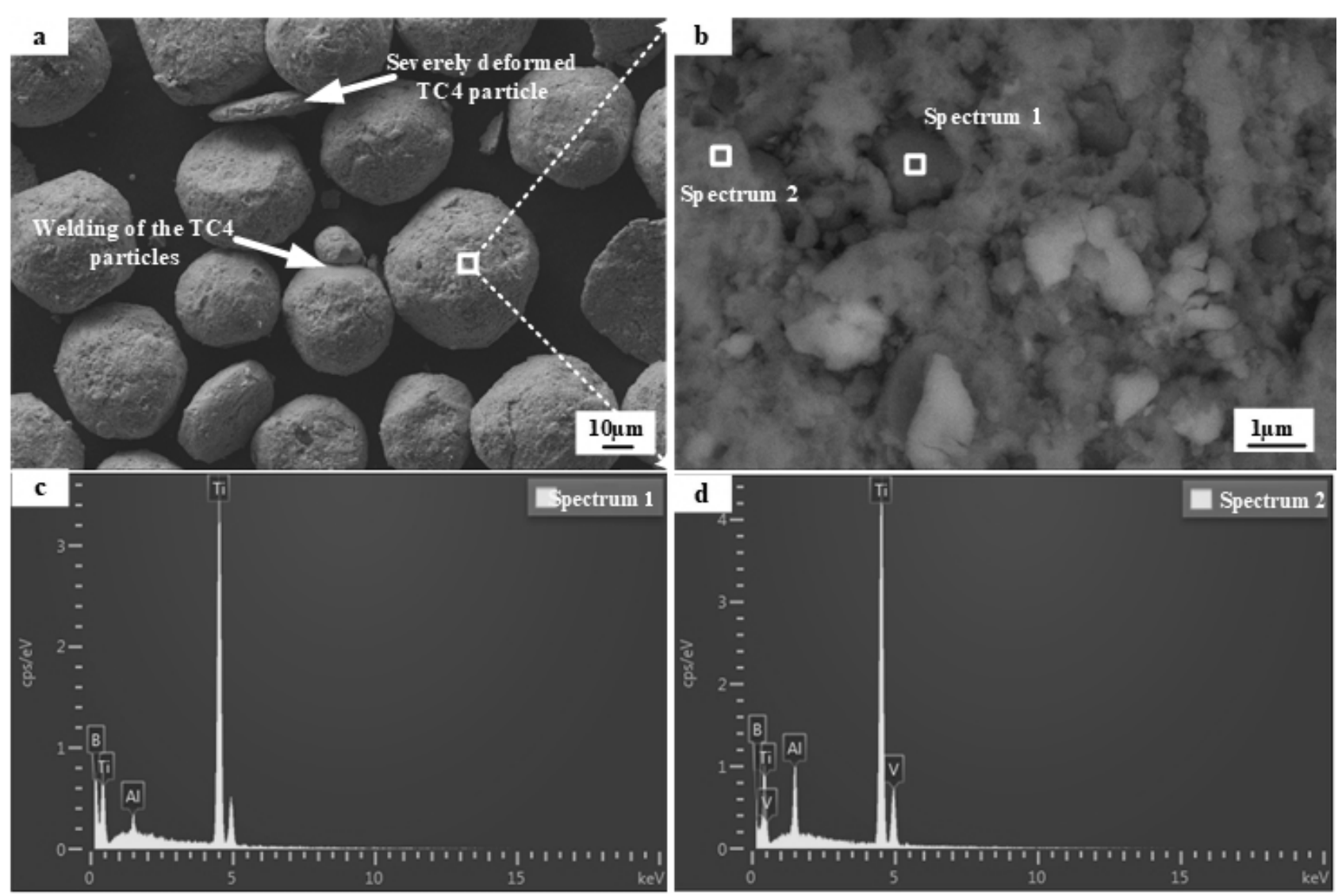

Fig.4 Partial enlarged view of milled TC4/TiB 2 powder (a), TiB 2 pinned to TC4 surface (b), and energy spectrum analysis of TC4 fragments at spectrum 1 (c) and spectrum 2 (d) in this region

(2) Wet ball milling powder mixing

The three powder samples obtained in the experiment VI-VIII are scanned by electron microscope and analyzed. The morphological images of wet ball milling mixed powder for $4 \mathrm{~h}, 6 \mathrm{~h}, 8 \mathrm{~h}$ are shown in Fig. 5 (a), 5 (b) and 5 (c).

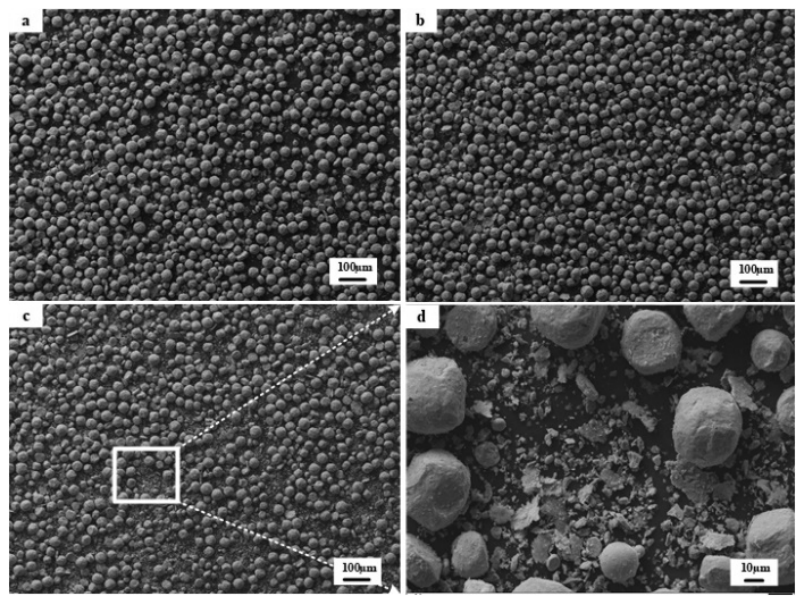

Fig. 5 Morphological images of wet ball milling mixed

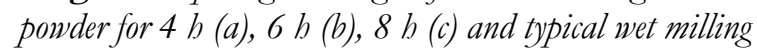
powder appearance (d)

The sphericity and surface of TC4 particle of the three working conditions mixed by wet mill is better than that by dry ball milling on the whole. The extruded particles of 6-hour wet milling mixed powder are more than that of 4-hour one, and a large number of fine powders can be observed. Large amount of broken and residual TC4 particles begin to appear 8hour wet milling mixed powder samples. The fine powders in Fig. 5 (c) are further enlarged as shown in Fig. 5 (d). It can be observed that there are flat block large particles, nearly spherical large particles and irregular small particles in the fine powder.

In order to determine the composition of these fine powder and whether the $\mathrm{TiB}_{2}$ particles are well pinned to the TC4 particles, the surface of TC4 particles and agglomerated small particles were observed and analyzed by energy spectrum as shown in Fig. 6. It is found that the surface of TC4 particles in the wet ball milling powder is smoother than that of the dry ball milling powder, and the number of small particles pinned to the surface is less, as shown in Fig. 6(a). Fig. 6(b) shows the spectrum 3 is $\mathrm{TiB}_{2}$ particle. Enlarge a part of the broken small agglomerated powder (see Fig. 6 (c)) and conduct energy spectrum analysis. The energy spectrum results are shown in Fig. 6 (d), (e) and (f). Spectrum 4 contains $\mathrm{B}, \mathrm{Ti}$ and $\mathrm{Al}$ elements, indicating that $\mathrm{TiB}_{2}$ particles and $\mathrm{TC} 4$ fragments exists in the area; Spectrum 5 contains $\mathrm{Ti}$ and $\mathrm{Al}$ elements, indicating that a small TC4 fragment is produced in the 
area by impacting; The region of spectrum 6 contains $\mathrm{B}$, Ti and $\mathrm{Al}$ elements, indicating that $\mathrm{TiB}_{2}$ particles and TC4 fragments exist in the region. The composition of crushed small powder is TC4 fragments, TC4 and $\mathrm{TiB}_{2}$ powder with initial small size. Therefore, the
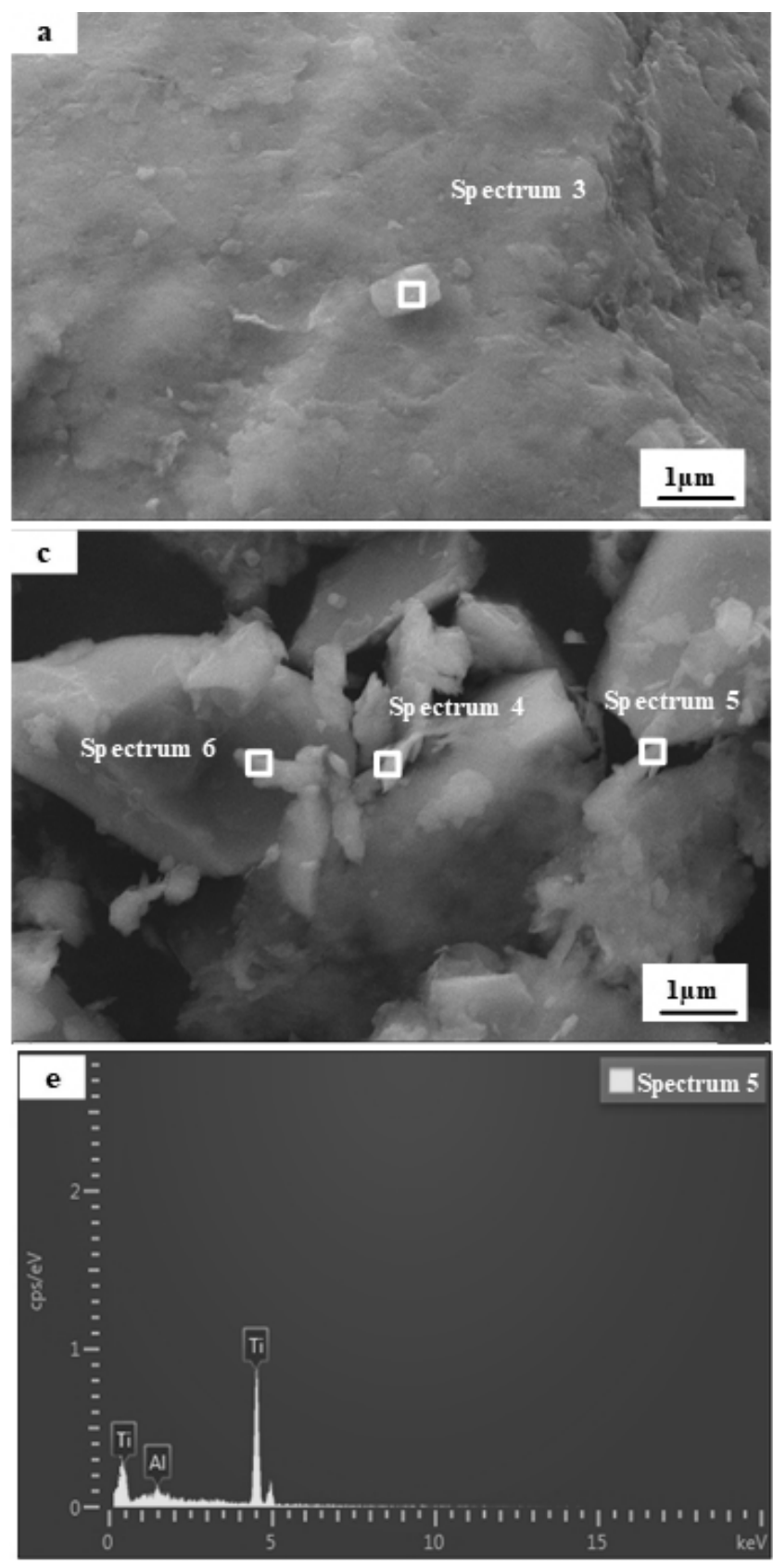

wet ball milling powder mixing is proved that the $\mathrm{TiB}_{2}$ can not be welded well to large TC4 particles, and the powder uniformity of wet ball milling is worse than that of dry ball milling, and there is a phenomenon of segregation of fine particles.
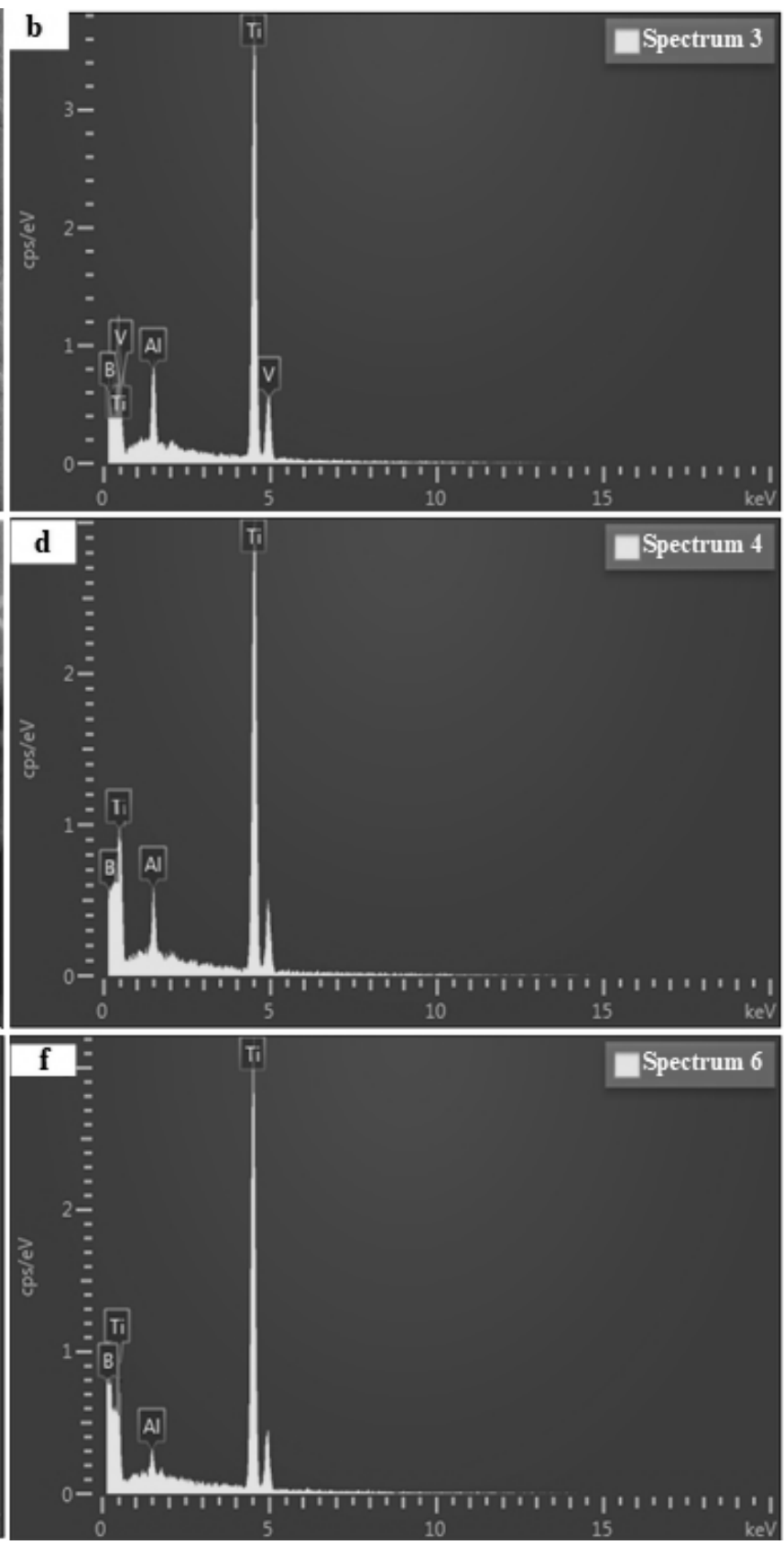

Fig. 6 TC4 particle surface(a) and energy spectrum analysis at spectrum 3(b), agglomerated small particles of wet milling mixed powder (c) and energy spectrum analysis at spectrum 4 (d), spectrum 5(e), spectrum 6 (f)

\section{(3) Hollow milling powder mixing}

The morphological images of hollow milling mixed powder for 4 h, 6 h, $8 \mathrm{~h}$ are shown in Fig. 7 (a), (b) and (c). It can be observed that the mixed powder with high sphericity can be obtained by hollow milling due to no extrusion force applied by the milling ball, and the sphericity of the mixed powder particles is almost the same at $4 \mathrm{~h}, 6 \mathrm{~h}$ and $8 \mathrm{~h}$. The longer the milling time, the more conducive to the fragmentation of small particle powder [16]. In addition, a small amount of fine particles can be observed distributing between the large TC4 spherical particles. In order to ascertain whether the small particles are pinned to the TC4 particle surface, the image of the mixed powder is enlarged as shown in Fig. 7 (d). It can be observed that many broken small particles are unevenly distributed on the surface of TC4. Since there is no impact and extrusion from the milling ball, the TC4 particle are 
almost impossible to be broken into small size one. Therefore, these small particles are assumed to be $\mathrm{TiB}_{2}$ one, energy spectrum analysis is carried out to determine the composition.

A part of the agglomerated area on the surface of TC4 sphere was taken for high-power electron microscope observation and energy spectrum analysis as shown in Fig. 8 (a) - (d). Fig. 8 (a) shows the TC4 surface of the hollow milling powder. Three points were taken for energy spectrum analysis according to the fragment distribution. Fig. 8 (b) - (d) show that the three points all contain a large amount of B element, indicating that these small fragments are $\mathrm{TiB}_{2}$ particles. This can prove that the $\mathrm{TiB}_{2}$ is uniformly pinned to the surface of TC4 by using hollow milling powder mixing. According to the analysis of the above 11 powder samples, it is concluded that a milling time 8 $\mathrm{h}$ at a speed of $230 \mathrm{rpm}$ without milling ball is proved the optimal working condition to make the composite powder maintain good spherical shape and ensure the
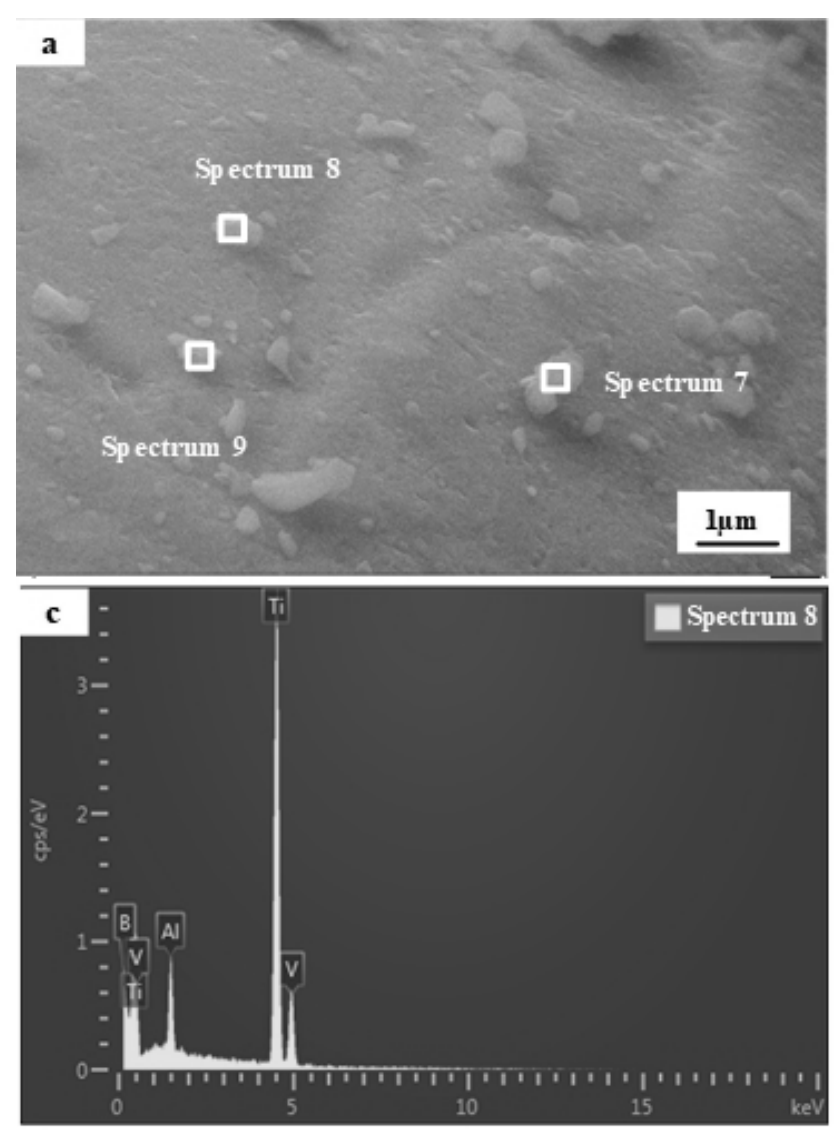

mixing uniformity.

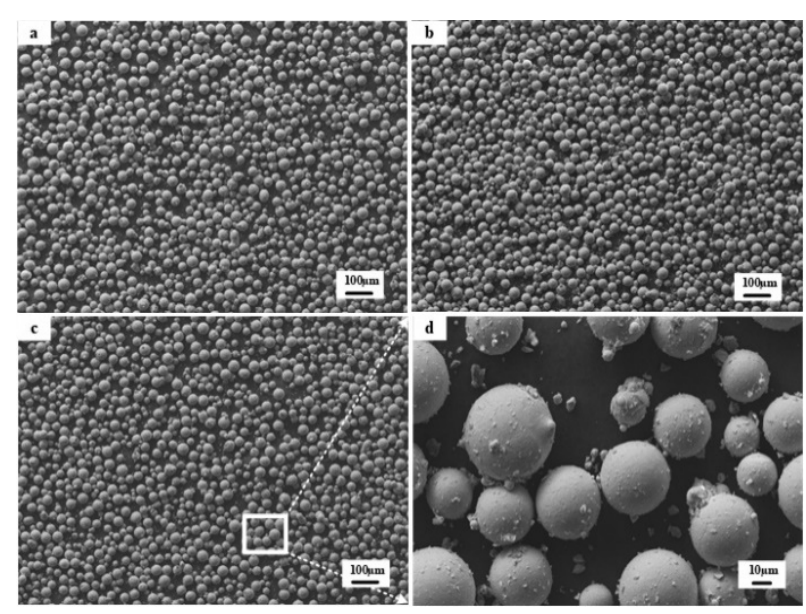

Fig. 7 Morphological images of hollow milling mixed powder for $4 \mathrm{~b}(\mathrm{a}), 6 \mathrm{~b}(\mathrm{~b}), 8 \mathrm{~b}(\mathrm{c})$, and typical hollow milling powder appearance (d)
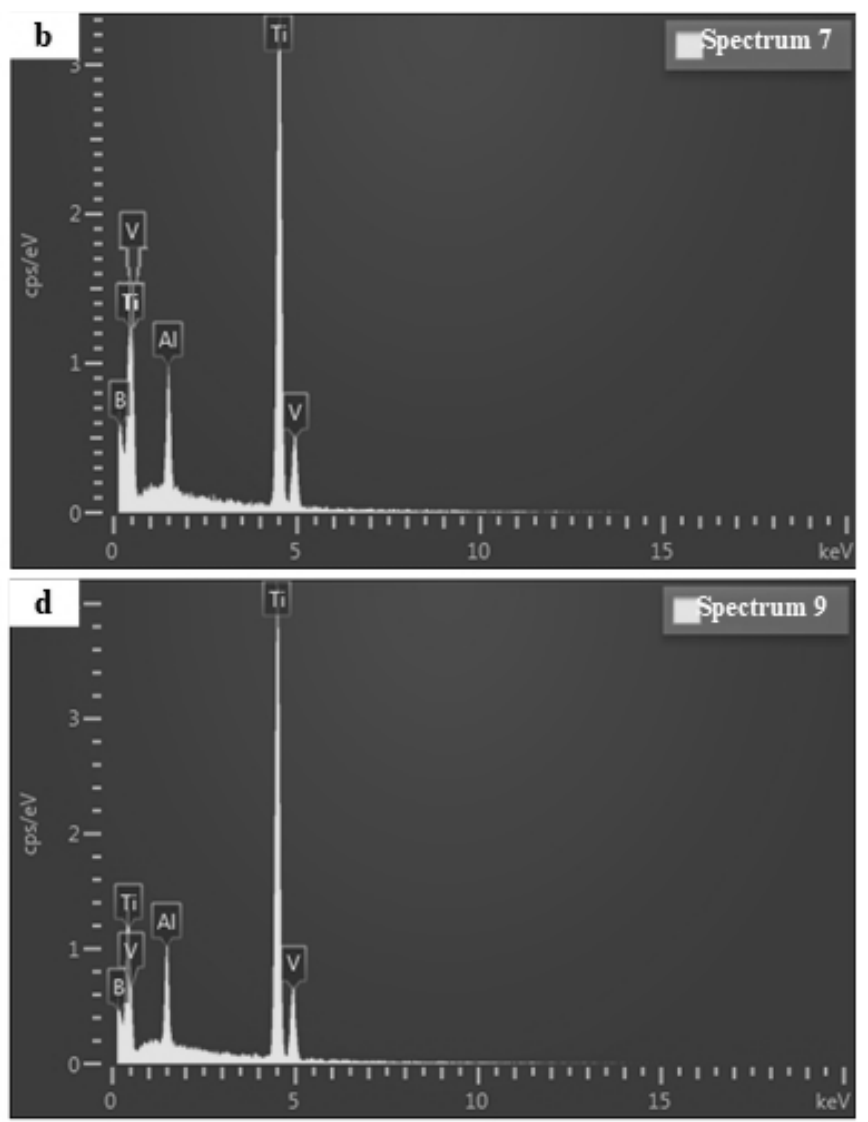

Fig. 8 Particles pinned to TC4 surface (a), and energy spectrum analysis at spectrum 7 (b), spectrum 8 (c) and spectrum 9 (d)

\subsection{Mechanism of three kinds of ball milling powder mixing methods}

In order to reveal the mechanism of the microscopic phenomenon generated by above three kinds of ball milling powder mixing methods, the hardness, volume and motion relationship of $\mathrm{ZrO}_{2}$ milling ball, $\mathrm{TC} 4$ and $\mathrm{TiB}_{2}$ particle are investigated. The hardness of $\mathrm{ZrO}_{2}$ can exceed $1250 \mathrm{HV}$; the hardness of TC4 titanium alloy is about $330 \mathrm{HV}$ and that of $\mathrm{TiB}_{2}$ is above $3900 \mathrm{HV}$. However, the volume ratio between the milling ball, TC4 particle and $\mathrm{TiB}_{2}$ particle is about 109:106:1. The Magini-Iasonna model [17] proposes that the energy transmitted to the unit mass powder during high-energy ball milling at each collision is: 


$$
\Delta \mathrm{E}=\frac{4.31 \times 10^{-2}}{\sigma\left(1 / \mathrm{E}_{1}+1 / \mathrm{E}_{2}\right)^{0.4}} \mathrm{R}_{\mathrm{p}}^{1.2} \varrho^{0.6} \mathrm{D}_{\mathrm{b}} \omega_{\mathrm{p}}^{1.2} \mathrm{Q}_{\max } \text { D] }
$$

Where:

$\Delta \mathrm{E}$...Energy obtained by powder collision []], $\sigma$...Surface density of covering powder $\left[\mathrm{mg} / \mathrm{mm}^{2}\right]$, $\mathrm{E}_{1}, \mathrm{E}_{2} \ldots$ Elastic modulus of milling ball and cylinder $\left[\mathrm{N} / \mathrm{m}^{2}\right]$,

$\omega_{\mathrm{p}}$... Mixing shaft speed [rpm],

$\mathrm{D}_{\mathrm{b}}$...Represents the diameter of ball milling medium [m],

Q...Ball material density $\left[\mathrm{kg} / \mathrm{m}^{3}\right]$,

$\mathrm{Q}_{\max } \ldots$ Total mass of composite powder [kg],

$\mathrm{R}_{\mathrm{p}}$...Rotation radius of the ball milling $[\mathrm{m}]$.

The schematic diagram of ball mill is shown in Fig. 9 (a). When the ball mill rotates, the $\mathrm{ZrO}_{2}$ milling ball has the maximum kinetic energy under the condition of the dry milling powder mixing. In case of different velocities, the softest TC4 particles are impacted and flattened. Then the smallest and hardest $\mathrm{TiB}_{2}$ particles are embedded or even welded on the surface of TC4 particles as shown in Fig. 9 (b). In the dry ball milling state, the composite powder is seriously deformed by the milling ball impact. The accumulated energy of the powder obtained is increases as the ball milling time, and the TC4 powder deformation worse $[18,19]$. For wet ball milling powder mixing, the ball milling medium, anhydrous ethanol, producing resistance $F$ in the opposite direction of the movements of the milling balls, $\mathrm{TC} 4$ and $\mathrm{TiB}_{2}$ particles, when the ball mill rotates. $\mathrm{F}$ is calculated by the following formula:

$$
\mathrm{F}=\frac{1}{2} \mathrm{CQV}^{2} \mathrm{~S}[\mathrm{~N}]
$$

\section{Where:}

C...Resistance constant [-],

Q...Density of the milling medium $\left[\mathrm{kg} / \mathrm{m}^{3}\right]$,

V...Movement speed $[\mathrm{m} / \mathrm{s}]$,

S...Contact area at the moving direction $\left[\mathrm{m}^{2}\right]$.

It can be found from Eq. (2) that the resistance increases with the growing up of the movement speed and contact area of the particles. Therefore, the milling balls with the largest contact area suffer the greatest resistance to reduce their kinetic energy (Fig. 9 (c)). And the impact of the milling ball on TC4 particles is weakened, so that a better sphericity of TC4 particle can be maintained. At the same time the $\mathrm{TiB}_{2}$ is not easy to be welded on the surface of TC4 particles.

For the hollow milling, all the impacts occur among the softer TC4 particles and tiny $\mathrm{TiB}_{2}$ particles due to no milling ball existing (Fig. 9 (d)). Few flattening and crushing situations occur on the larger TC4 particles due to their having the same hardness and similar volume, and the harder $\mathrm{TiB}_{2}$ particles are also welded on their surfaces easily under the impacts of the TC4 particles.

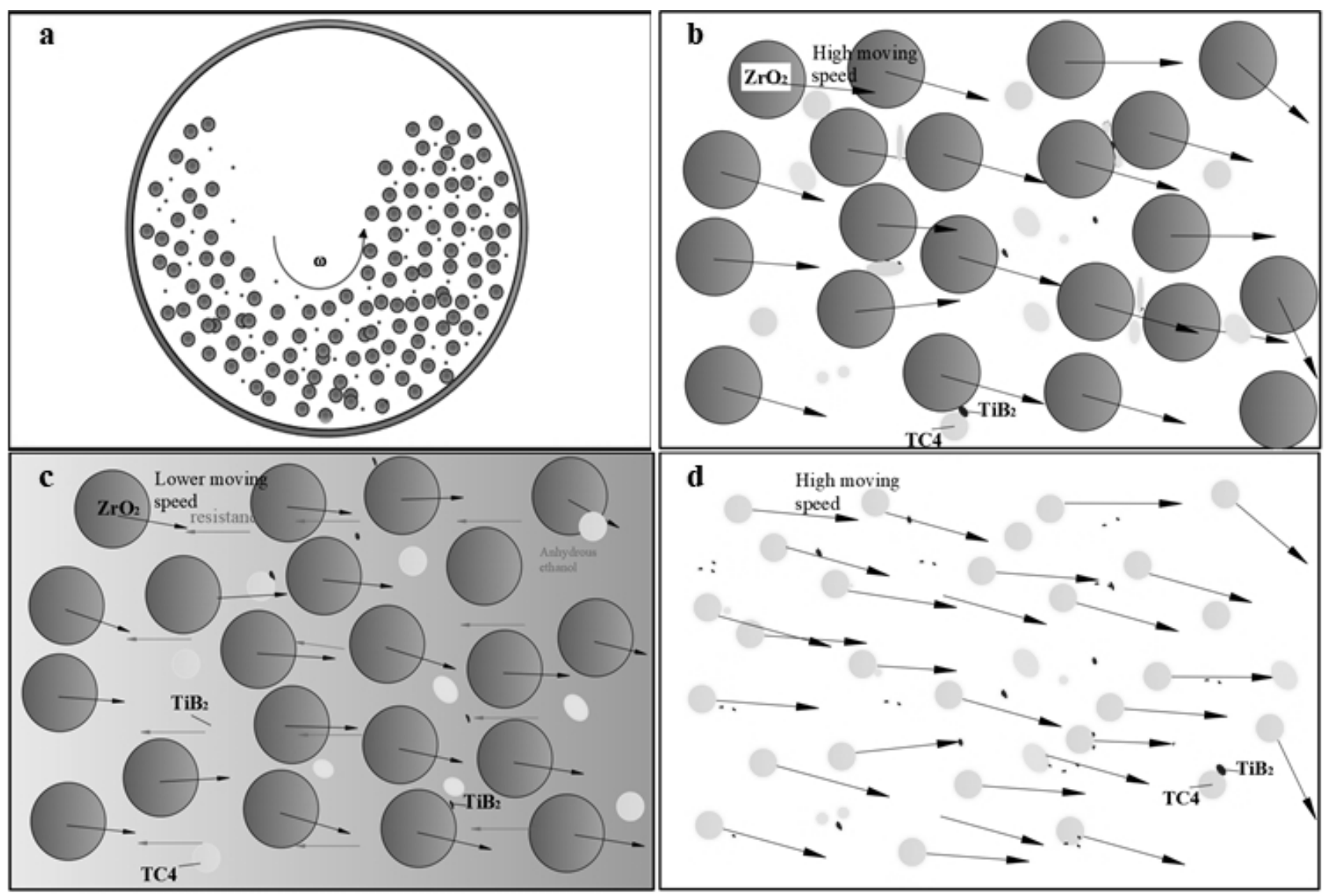

Fig. 9 Scheme of the planetary ball mill (a), mechanism diagram of three kinds of ball milling powder mixing methods, (b) dry ball milling, (c) wet ball milling and (d) bollow milling 


\subsection{SLM experiment on milled $\mathrm{TC} 4 / \mathrm{TiB}_{2}$ powder}

The $\mathrm{TC} 4 / \mathrm{TiB}_{2}$ mixed powder prepared by the best working condition is used in the SLM experiment. The powder mixing parameters are $\mathrm{wt} \% 95 \mathrm{TC} 4$ with $\mathrm{wt} \%$ $5 \mathrm{TiB}_{2}$ hollow milling powder mixing. The rotating speed of the ball mill is $230 \mathrm{rpm}$, the milling time is 8 hours. The BLT-S210 SLM equipment is adopted to carried out the experiment as shown in Fig. 10. The SLM processing parameters are set as: scanning spacing $80 \mu \mathrm{m}$; laser power $200 \mathrm{~W}$, area energy density $210 \mathrm{KJ} / \mathrm{cm}^{2}$.

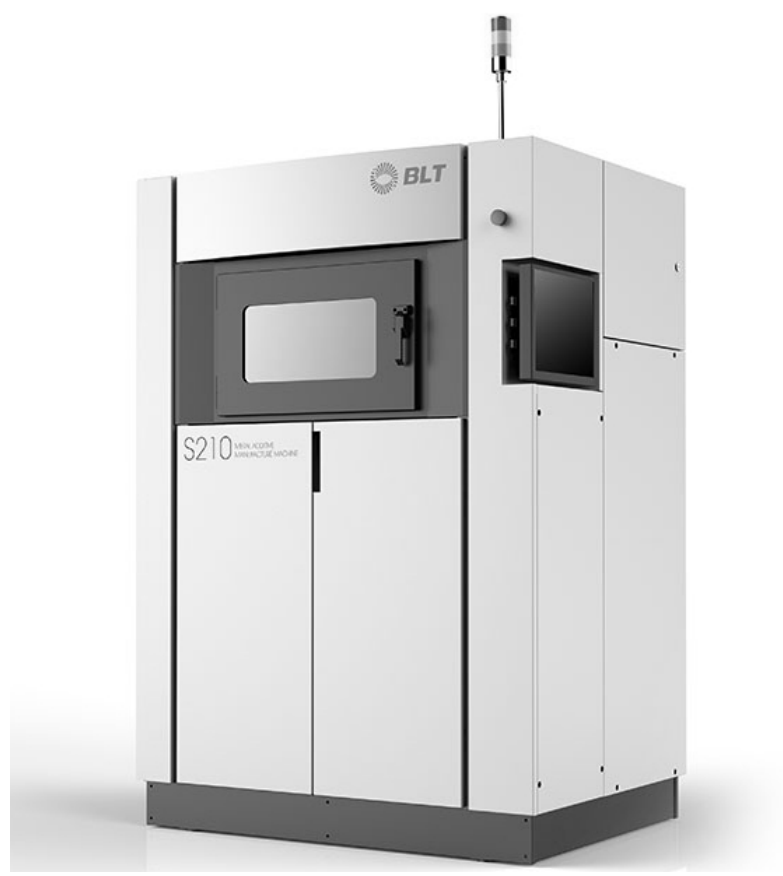

Fig. 10 BLT-S210 SLM equipment

The SLM forming part using the mixed powder have no surface pores, the deposition melting pool is regular and orderly. Then the formed part is prepared sample, polished and metallographic observed. It can be found that the solidifying structure continuity is high, and the density of the formed parts is good as shown in Fig. 11.

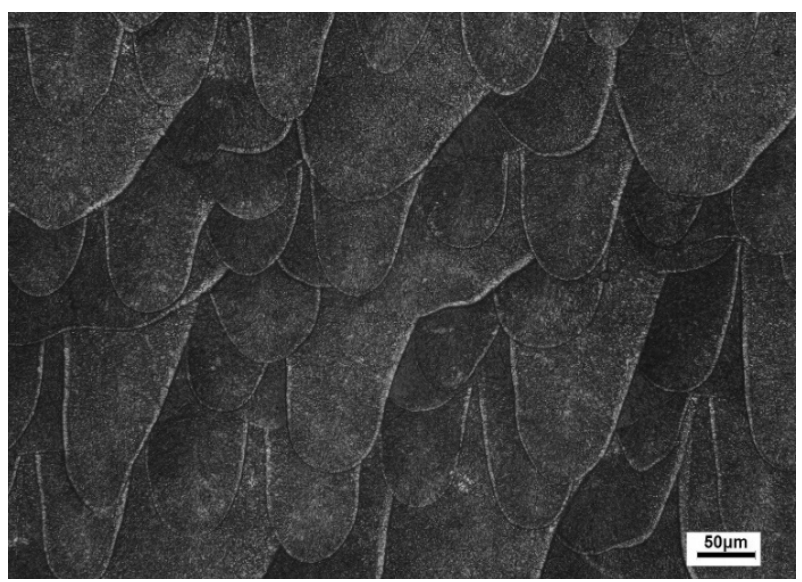

Fig. 11 Micro morphology of the SLM forming part

\section{Conclusion}

Three kinds of ball milling methods, dry ball milling, wet ball milling and hollow milling, for SLM are proposed. The powder mixing effects of the three methods are evaluated by electron microscopy observation and energy spectrum analysis. The mechanism of three powder mixing effects is revealed. The main conclusions are as follows:

(1) The TC4 particle surface becomes rough after dry ball milling, the powder sphericity is seriously damaged with the long dry ball milling time. And the number and maximum size of flat particles increased as the ball milling length increased. However, the tiny $\mathrm{TiB}_{2}$ particle can pin to the surface of TC4 one during dry ball milling mixing.

(2) Wet ball milling can not ensure the $\mathrm{TiB}_{2}$ particles to be pinned (or welded) to the surface of large TC4 particles, but the sphericity of the TC4/ $\mathrm{TiB}_{2} \mathrm{mi}-$ xed powder obtained by this method is much better than that by dry ball milling one.

(3) Hollow milling can not only make the two powders with great particle size difference mix evenly, but also cause the small $\mathrm{TiB}_{2}$ particles to be pinned to the surface of the large TC4 particles. At the same time, the intact sphericity of TC4 particles can be maintained with the best powder mixing effect in the three methods.

(4) The mechanism of three kinds of powder mixing effects is revealed as that, dry ball milling has the largest $\mathrm{ZrO}_{2}$ milling ball and the maximum impact kinetic energy. In addition, the milling ball is much harder than TC4 particles. However, the impact kinetic energy is greatly weakened by the ball milling medium in the wet milling powder mixing process. While the hardness of the TC4 particles with the largest volume is almost the same in the hollow milling process. Therefore, the above three kinds of powder mixing effects are produced.

\section{Acknowledgement \\ This work was financially supported by National Key R\&D Program of China (2018YFB1105805), and authors wish to express their gratitude.}

\section{References}

[1] GEETHA M, SINGH A K, ASOKAMANI R, et al. Ti based biomaterials, the ultimate choice for orthopaedic implants-A review[J]. Progress in Materials Science, 2009, 54(3):397-425.

[2] HOEJIN KIM, YIRONG LIN, TZU-LIANG BILL TSENG. A review on quality control in additive manufacturing[]. Rapid Prototyping Journal, 2018, 24(3): 645-669.

[3] YAHYA AL-MESLEMI, NABIL ANWER, LUC MATHIEU. Environmental Performance 
and Key Characteristics in Additive Manufacturing: A Literature Review[J]. Procedia CIRP, 2018, 69: 148-153.

[4] DIPANKAR, BANERJEE, J. C, et al. Perspectives on Titanium Science and Technology[]. Acta Materialia, 2013.

[5] AHMADI S M, YAVARI S A, WAUTHLE R, et al. Additively Manufactured Open-Cell Porous Biomaterials Made from Six Different Space-Filling Unit Cells: The Mechanical and Morphological Properties[J]. Materials, 2015, $8(4)$.

[6] QIYUN YANG. Study on Properties of Inconel 625 Alloy Powder and Products in Selective Laser Melting[D]. General Research Institute of Mechanical Science,2016. (in Chinese)

[7] DENG PAN et al. TiB nano-whiskers reinforced titanium matrix composites with novel nano-reticulated microstructure and high performance via composite powder by selective laser melting[]. Materials Science \& Engineering A, 2021, 799 .

[8] ROUDNICKA M, MISURAK M, VOJTECH D. Differences in the Response of Additively Manufactured Titanium Alloy to Heat Treatment - Comparison between SLM and EBM[J]. Manufacturing Technology, 2019, 19(4):688-673.

[9] VONAVKOVA I, VOJTECH D, PALOUSEK D. Characterization of $\beta$-Ti alloy prepared by SLM method[J]. Manufacturing Technology, 2020, 20(5):690-696.

[10] ZHENG DAN, LI RUIDI, SONG BO, XIONG YI, YUAN TIECHUI, SHI YUSHENG, Effect of NiTi Powder Gas Atomization Process on the Selective Laser Melting Moldability and Alloy' Superelastic, Journal of mechanical engineering [], 2020, 56(15): 118-123. (in Chinese)
[11] ATTAR H, BÖNISCH M, CALIN M, et al. Selective laser melting of in situ titanium-titanium boride composites: Processing, microstructure and mechanical properties[]. Acta Materialia, 2014, 76:13-22.

[12] YANG CHAO, Effect of ball milling process on Microstructure and mechanical properties of CNTs / Al Composites, Kunming University of Technology [D], 2017 (in Chinese)

[13] ATTAR H, GPRASHANTH K, ZHANG L C, et al. Effect of Powder Particle Shape on the Properties of In Situ Ti-TiB Composite Materials Produced by Selective Laser Melting[]. Material Science and Technology (in English), 2015.

[14] SHEN C L, SHI J M, ZHANG L, LONG X G, Effect of ball milling technics on B4C-Al composite performance. Journal of Functional Materials [J], 2011, 42: 365-369. (in Chinese)

[15] HYE JIN JUNG, YOUNGKU SOHN, HONG GYE SUNG, HYUNG SOO HYUN, WEON GYU SHIN. Physicochemical properties of ball milled boron particles: Dry vs. wet ball milling process[]]. Powder Techno$\log y, 2015,269: 548-553$.

[16] SARODE VIJAY B, PATIL AVINDRA D. Experimental analysis of effect of speed and time on aluminium nanoparticles fabricated by high energy ball milling[J]. IOP Conference Series: Materials Science and Engineering,2021,1166(1).

[17] M. MAGINI, A. IASONNA. Energy Transfer in Mechanical Alloying (Overview)[]]. The Japan Institute of Metals, 1995, 36(2).

[18] V.K. GUPTA. Effect of size distribution of the particulate material on the specific breakage rate of particles in dry ball milling[J]. Powder Tecbnology, 2017, 305: 714-722.

[19] GUPTA V.K. Energy absorption and specific breakage rate of particles under different operating conditions in dry ball milling[]. Powder Technology, 2020, 361(C): 827-835. 